\title{
Stem cells in cancer therapy: opportunities and challenges
}

\author{
Cheng-Liang Zhang ${ }^{1}$, Ting Huang ${ }^{1}$, Bi-Li Wu ${ }^{2}$, Wen-Xi He ${ }^{1}$ and Dong Liu ${ }^{1}$ \\ ${ }^{1}$ Department of Pharmacy, Tongji Hospital, Tongji Medical College, Huazhong University of Science and Technology, Wuhan, \\ Hubei Province, China \\ ${ }^{2}$ Department of Oncology, Tongji Hospital, Tongji Medical College, Huazhong University of Science and Technology, Wuhan, \\ Hubei Province, China
}

Correspondence to: Dong Liu, email: Id2069@outlook.com

Keywords: stem cell, targeted cancer therapy, tumor-tropic property, cell carrier

Received: June 22, 2017 Accepted: August 17, $2017 \quad$ Published: September 08, 2017

Copyright: Zhang et al. This is an open-access article distributed under the terms of the Creative Commons Attribution License 3.0 (CC BY 3.0), which permits unrestricted use, distribution, and reproduction in any medium, provided the original author and source are credited.

\section{ABSTRACT}

Metastatic cancer cells generally cannot be eradicated using traditional surgical or chemoradiotherapeutic strategies, and disease recurrence is extremely common following treatment. On the other hand, therapies employing stem cells are showing increasing promise in the treatment of cancer. Stem cells can function as novel delivery platforms by homing to and targeting both primary and metastatic tumor foci. Stem cells engineered to stably express various cytotoxic agents decrease tumor volumes and extend survival in preclinical animal models. They have also been employed as virus and nanoparticle carriers to enhance primary therapeutic efficacies and relieve treatment side effects. Additionally, stem cells can be applied in regenerative medicine, immunotherapy, cancer stem cell-targeted therapy, and anticancer drug screening applications. However, while using stem cells to treat human cancers appears technically feasible, challenges such as treatment durability and tumorigenesis necessitate further study to improve therapeutic performance and applicability. This review focuses on recent progress toward stem cell-based cancer treatments, and summarizes treatment advantages, opportunities, and shortcomings, potentially helping to refine future trials and facilitate the translation from experimental to clinical studies.

\section{INTRODUCTION}

Cancer is a leading cause of death in both developed and developing countries, and is an increasing medical burden worldwide, due to population growth and aging. Cancer is mainly treated using surgical resection, fractionated radiotherapy, and chemotherapy. However, treatment-related side effects, off-target effects, and drug resistance limit the efficacies of many therapeutic options. Furthermore, metastatic cancer cells usually cannot be eliminated by traditional therapies, and recurrence in these cases is extremely likely. Therefore, researchers are working to develop new, effective therapies with low or no toxicity in normal cells.

Stem cells have unique properties, such as migration toward cancer cells, secretion of bioactive factors, and immunosuppression, which promote tumor targeting and circumvent obstacles currently impeding gene therapy strategies. Preclinical stem cell-based strategies show great promise for use in targeted anti-cancer therapy applications. Nevertheless, there remain scientific concerns regarding the use of stem cell therapies, and further studies are needed to validate preclinical findings. This review summarizes recent anti-cancer stem cell therapy studies, and identifies advantages, opportunities, and potential challenges.

\section{STEM CELL DEFINITIONS AND SOURCES}

As a unique population, stem cells are defined by their ability to: 1) self-renew indefinitely, 2) form single cell-derived clonal cell populations, and 3) differentiate into various cell types [1]. Self-renewal in resident stem cell pools plays key roles in tissue regeneration and homeostasis [2]. Stem cells can be broadly categorized as 'embryonic' (ESCs) or 'somatic' (SSCs). SSCs are 
also known as adult stem cells, which are generally multipotent and can differentiate into any cell type with a specific lineage, including neural stem cells (NSCs), mesenchymal stem cells (MSCs), hematopoietic stem cells (HSCs), endothelial progenitor cells (EPCs), and others. In at least some cases, cancer stem cells (CSCs) may drive tumorigenesis and disease progression [3].

\section{ESCs and iPSCs}

As pluripotent cells, ESCs can differentiate into all cell types except those in the placenta [4], and are therefore used as gold standards in the evaluation of all pluripotent cells cultured in vitro. However, due to ethical considerations, applications for ESCs in scientific studies and human clinical trials are restricted. To this end, ESCs can be replaced by induced pluripotent stem cells (iPSCs) reprogrammed from adult somatic cells (e.g. skin fibroblasts) through enforced expression of pluripotency factors, because iPSC establishment does not require embryo destruction [5]. iPSCs are similar to ESCs, but lack immunogenic or ethical limitations, and so may be more clinically applicable than ESCs.

\section{NSCs}

NSCs are typified by expression of nestin, Sox 2, and other classic markers, together with expansion in culture media rich in epidermal and fibroblast growth factors [6]. NSCs can self-renew and differentiate into astrocytes, neurons, or oligodendrocytes, and have been widely employed to treat brain, breast [7], prostate [8], and lung [9] tumors.

\section{MSCs}

MSCs are derived from bone marrow and can differentiate into mesodermal cells, including cartilage, bone, adipose tissue, stroma, muscle, connective tissue, and tendon. MSCs are easily isolated and propagated in vitro and, like NSCs, are applied widely in the treatment of different cancers.

\section{HSCs}

HSCs, the most primitive of the blood lineage cells, are predominantly found in bone marrow, and produce mature blood cells through proliferation and differentiation of increasingly lineage-restricted progenitors. Transplantation of HSCs has been employed clinically for over four decades.

\section{EPCs}

EPCs are the primary drivers of vascular regeneration [10]. Asahara, et al. suggest potential utility for EPCs in cancer therapy, following transfection or coupling with antitumor drugs or angiogenesis inhibitors [11]. However, recent advances have shifted the focus to EPC roles in disease pathogenesis and potential benefits as part of therapeutic interventions [10]. Reports on EPCs in cancer therapy are rare.

\section{CSCs}

Based on cell surface markers, CSCs, a stemlike cancer cell subpopulation, are isolated from patient tissues and cell lines of different cancer types. CSCs express stemness genes, self-renew, differentiate into other non-stem cancer cells, and resist traditional cancer treatments [3]. CSCs likely initiate many cancer types. Traditional cancer therapies can kill non-stem cancer cells, but cannot eliminate CSCs. Tumors usually relapse when the remaining CSCs proliferate and differentiate. Therefore, targeting CSCs may solve clinical issues like drug resistance and recurrence [12].

\section{STEM CELL PROPERTIES}

In addition to their self-renewal and differentiation capabilities, stem cells have immunosuppressive, antitumor, and migratory properties. Because stem cells express growth factors and cytokines that regulate host innate and cellular immune pathways [13, 14], they can be manipulated to both escape the host immune response and act as cellular delivery agents. Stem cells can also secret factors, such as CCL2/MCP-1, and physically interact with tumor cells, changing co-cultured tumor cell phenotypes and exerting intrinsic antitumor effects [15].

Importantly, many human stem cells have intrinsic tumor-tropic properties that originate from chemokinecancer cell interactions. Stem cells first exhibited migratory capabilities in xenograft mouse models, manifested as tumor-homing abilities [16]. Possible stem cell migration mechanisms have been extensively studied. NSC migration to tumor foci is triggered by hypoxia, which activates expression of chemoattractants [6]. Directional HSC migration depends on the interaction between chemokine, CXCL12, and its receptor, CXCR4 [17]. A variety of MSC-expressed chemokine and growth factor receptors may participate in tumor homing [18]. The stromal cellderived factor 1 (SDF1)/CXCR4 axis plays a major role in the migration of various stem cells [19-21]. To improve directed homing, stem cells have been engineered with higher levels of chemokine receptors, or target tissues have been manipulated to release more chemokines [22]. Park, et al. reported that CXCR4-overexpressing MSCs migrated toward glioma cells more effectively than control MSCs in vitro and in a xenografted mouse model of human glioma [20]. Controlled release of a chemokine from various biomaterials enhances recruitment of stem cells towards them. Schantz et 
Table 1: Applications of stem cells in cancer therapy

\begin{tabular}{|c|c|c|c|}
\hline Strategies & Cancer types & Stem cell applications & References \\
\hline \multicolumn{4}{|l|}{ Stem cell modifications } \\
\hline \multirow[t]{6}{*}{ Enzyme/prodrug therapy } & Glioma & NSCs (retroviral transduction with CD) & {$[16,26]$} \\
\hline & & NSCs (baculoviral transduction with HSV-TK) & [29] \\
\hline & & $\begin{array}{l}\text { MSCs (lentiviral and retroviral transduction with } \\
\text { S-TRAIL and HSV-TK) }\end{array}$ & [27] \\
\hline & & MSCs (retroviral transduction with CD ) & [25] \\
\hline & Colon adenocarcinoma & NSCs (adenovirus transduction with a rabbit CE) & [26] \\
\hline & $\begin{array}{l}\text { Metastatic lung cancer } \\
\text { and primary lung cancer }\end{array}$ & NSCs (engineered to express CE) & [9] \\
\hline \multirow[t]{5}{*}{ Secreted agents } & Glioma & NSCs (retrovirus transduction with IL-4 ) & [26] \\
\hline & & NSCs (adenovirus transduction with TRAIL) & [26] \\
\hline & & $\begin{array}{l}\text { NSCs (encapsulated in sECM after being } \\
\text { engineered to express S-TRAIL) }\end{array}$ & [32] \\
\hline & $\begin{array}{l}\text { Breast cancer brain } \\
\text { metastases }\end{array}$ & $\begin{array}{l}\text { NSCs (lentivirus transduction with anti- } \\
\text { HER2Ab) }\end{array}$ & [7] \\
\hline & Breast cancer & MSCs (engineered to over express IFN-beta) & [33] \\
\hline \multirow[t]{3}{*}{ Viral therapy } & Glioma & NSCs (infected with CRAd-S-pk7) & {$[35,67]$} \\
\hline & & MSCs (loaded with oHSV) & [38] \\
\hline & $\begin{array}{l}\text { Hepatocellular } \\
\text { carcinoma }\end{array}$ & MSCs (infected with measles virus) & [37] \\
\hline \multirow[t]{3}{*}{ Nanoparticle carriers } & Solid tumor & NSCs (loaded with gold nanorods) & [40] \\
\hline & Glioma & $\begin{array}{l}\text { MSCs (loaded with poly-lactic acid nanoparticles } \\
\text { and lipid nanocapsules) }\end{array}$ & [41] \\
\hline & & MSCs (loaded with nanoparticles) & [42] \\
\hline \multirow[t]{2}{*}{ Regenerative medicine } & $\begin{array}{l}\text { Hematologic } \\
\text { malignancies }\end{array}$ & HSCs (allogeneic transplantation) & [44] \\
\hline & Liver disease & iPSCs (engraftment of patient-specific iPSCs) & {$[45,46]$} \\
\hline \multirow[t]{4}{*}{ Immunotherapy } & Solid tumor & HSCs (induction of graft vs. tumor effect) & [48] \\
\hline & Lymphomas & HSCs (allogeneic transplantation) & [49] \\
\hline & & iPSCs (generate T cells) & [53] \\
\hline & Melanoma & $\begin{array}{l}\text { HSCs (genetically engineered HSCs to generate } \\
\text { antigen-specific CD } 8 \text { T cells) }\end{array}$ & [51] \\
\hline Targeting CSCs & Glioma & HSCs (modifying the proteome profile of HSCs ) & [57] \\
\hline Anticancer drug screening & l & $\begin{array}{l}\text { cancer tissue-derived iPSCs (provide cellular } \\
\text { targets) }\end{array}$ & [59]. \\
\hline
\end{tabular}

al. achieved site-specific homing of MSCs toward a cellular polycaprolactone scaffold, which was constantly releasing SDF-1 with micro delivery device in vivo [23]. Thus, these two strategies can be combined to increase homing efficiency and improve treatment outcomes.

\section{STEM CELL MODIFICATIONS FOR CANCER THERAPY}

Stem cells, most commonly NSCs and MSCs, can be modified via multiple mechanisms for potential use in cancer therapies. Common modifications include the therapeutic enzyme/prodrug system, and nanoparticle or oncolytic virus delivery at the tumor site.

\section{Enzyme/prodrug therapy}

NSCs and MSCs can be engineered to express enzymes that convert non-toxic prodrugs into cytotoxic products. When modified stem cells are transplanted into tumor-bearing models, they localize to tumor tissues, where the exogenous enzyme converts the prodrug into 
a cytotoxic molecule, ultimately damaging the tumor cells. As a result, the amount, timing, and location of drug release can be precisely controlled. Enzyme/prodrug therapy is also called suicide gene therapy, and was the first engineered NSC therapeutic application and the first to enter clinical trials $[16,24]$.

Cytosine deaminase (CD) is a major enzyme currently used in enzyme/prodrug therapy. CD converts the prodrug, 5-fluorocytosine (5-FC), into the toxic variant, 5-fluorouracil. Aboody, et al. reported that the combination of CD-bearing mouse NSCs and 5-FC inhibited glioblastoma (GBM) cell growth [16]. Injecting CD-expressing MSCs into the brain with 5-FC also suppressed tumor growth [25]. In one of the most commonly used cytotoxic therapies, human HB1.F3 cells are engineered to express CD (HB1.F3.CD) [26]. With outstanding efficacy and safety, HB1.F3.CD/5-FC therapy was recently applied in the first human clinical trial (ClinicalTrials.gov identifier: NCT01172964), in which HB1.F3.CD cells were injected into the cavity wall following GBM resection, and patients received oral 5-FC [24]. This study was completed, and results have not yet been released. Another trial (ClinicalTrials.gov identifier: NCT02015819) using modified NSCs to treat glioma will be completed in October 2018.

Herpes simplex virus-thymidine kinase (HSV-TK) has also been utilized in suicide gene therapy [27]. HSVTK phosphorylates the prodrug, monophosphorylate ganciclovir (GCV), to produce cytotoxic triphosphate ganciclovir (GCV-TP). GCV-TP integrates into the DNA of nearby cells during division, leading to cell death via DNA polymerase inhibition. Li, et al. reported that C6 gliomas in rats were effectively treated by intratumoral HSV-TK-transduced NSC (NSC-TK) injection followed by intraperitoneal GCV injection daily for 10 days (two $15 \mathrm{mg} / \mathrm{kg}$ doses/day). Six of nine rats survived 100 days post-injection, without any signs of tumor [28]. Another study showed that NSCs-TK injected into the brain migrated to the contralateral hemisphere, co-localized with U87 cells, and conferred long-term survival on GCVtreated mice [29].

\section{Secreted agents}

Stem cells can function as in situ drug factories, secreting antitumor agents for an extended period of time, and overcoming various cancer therapy limitations, such as high systematic toxicity and short drug half-life. TNF$\alpha$-related apoptosis-inducing ligand (TRAIL) is one of the most widely used, secreted therapeutic agents, and induces tumor cell apoptosis [30]. However, its short halflife reduces its therapeutic effectiveness in vivo [31]. This could be mitigated by encapsulating TRAIL-expressing stem cells in a synthetic extracellular matrix (sECM) that is introduced into the GBM resection cavity after surgical debulking [32]. The encapsulated cells could continually release therapeutic molecules at resection margins. This approach delays malignant and invasive brain tumor regrowth and increases survival in mice.

Stem cells can also be modified to selectively deliver growth inhibitory proteins (e.g. IFN- $\beta$ ), rendering the microenvironment inhospitable to tumor growth. Ling, et al. studied the migration of IFN- $\beta$-expressing MSCs and their engraftment into primary breast tumor sites, and found that tumor cell growth was suppressed, and hepatic and pulmonary metastases were alleviated [33]. MSCs secreted IFN- $\beta$ at high levels in the tumor microenvironment but not in the circulation. This study also suggested that in situ IFN- $\beta$ expression in MSCs suppressed or abrogated cancer cell growth by inactivating signal transducer activator transcription factor 3 (Stat3).

\section{Viral therapy}

Oncolytic viruses (OVs), unlike traditional attenuated viruses, conditionally replicate in tumor cells. OVs have increased spread in the body and hide from the immune system. OV-transduced NSCs are still able to home to tumor cells, and NSC-delivered OVs showed better antitumor effects than the viruses alone against GBMs in vivo [34]. Similarly, after radiotherapy and temozolomide treatment, NSC-delivered OVs increased survival in glioma bearing mice [35]. Early clinical trials for antiglioma gene therapies based on adenovirus vectors reported sufficient tolerabilities without serious adverse events [36].

Virus delivery by MSCs is also a promising approach for targeted cancer therapy. Ong, et al. demonstrated that the potent oncolytic activity of attenuated measles virus combined with the unique immunoprivileged and tumortropic properties of MSCs could combat hepatocellular carcinoma [37]. Systemically delivered measles virusinfected MSCs homed to tumors implanted orthotopically in the liver and transferred MV infectivity to cancer cells via heterofusion, inhibiting tumor growth. Duebgen, et al. showed that MSC-mediated delivery of oncolytic herpes simplex virus (oHSV) in a GBM resection mouse model enhanced the virus' antitumor effects [38]. In this approach, oHSV produced by MSC dynamically infected GBM cells, killing tumor cells in vitro and in vivo. Combining oHSV with TRAIL may also effectively avoid resistance in tumors. oHSV/TRAIL-loaded MSCs effectively induced tumor cell apoptosis and extended median survival time in mice bearing oHSV- and TRAILresistant GBMs [38].

\section{Nanoparticle carriers}

Delivery systems based on nanoparticle carriers (NPs) often contain high-concentration insoluble chemotherapeutic reagents, and protect them from degradation in a harsh biological environment. Failure to 
target micrometastatic lesions, inefficient dissemination in solid tumors, and other limitations can be overcome by using stem cells as NP delivery agents [39, 40]. Stem cells can also reduce unrestricted uptake of nanoparticles by mononuclear cells and protect therapeutic agents from host immunosurveillance [39]. Roger, et al. found that MSCs efficiently internalized NPs and could act as NP delivery vehicles in brain tumors [41]. MSC cell membranes can be loaded with doxorubicin-containing porous silica nanorattles for tumor-tropic therapy [42]. This approach increased and extended intratumoral drug distribution and promoted tumor cell apoptosis more than free drug or drug delivery systems using silica nanorattles alone. Thus, stem cell-mediated NP-based drug delivery shows great promise in cancer treatments, and warrants further investigation.

\section{OTHER APPLICATIONS OF STEM CELL IN CANCER THERAPY}

\section{Regenerative medicine}

Given their self-renewal and differentiation capabilities, stem cells can be used to repair human tissues after chemotherapy. Transplanting HSCs has been widely clinically employed to facilitate lifelong hematological recovery after treatment of malignancies with high-dose radiotherapy or chemotherapy. This treatment aims to reconstitute bone marrow under marrow failure conditions (e.g. aplastic anemia) and to treat blood cell genetic diseases, and works by supplying stem cells that differentiate into a desired type of blood cell. Transplantation and successful engraftment of only one HSC can reconstitute hematopoiesis in recipients [43, 44].

Healthy iPSCs derived from patient tissues can theoretically be employed to regenerate tumor- or treatment-injured tissues. In regenerative medicine, various tissues can be produced using iPSCs. iPSC therapy may be useful in repairing or replacing cancer patient iPSCs damaged by chemotherapy, radiotherapy, or surgical treatment. However, regenerative therapy mediated by human iPSCs requires robust in vivo engraftment of iPSC-derived tissues. Currently, only a few types of human iPSC-derived cells (e.g. hepatocytes) have been successfully engrafted in animal models $[45,46]$.

\section{Immunotherapy}

An immune-mediated antitumor effect following allogeneic HSC transplantation might be sufficient to cure some hematological malignancies [47-49]. Introducing genes encoding chimeric antigen receptors (CARs) or T-cell receptors (TCRs) directed against tumor-associated antigens makes HSCs attractive for use in cancer immunotherapy $[50,51]$.
Patient-specific iPSCs could also potentially benefit immunotherapy approaches $[52,53]$. The pre-rearranged TCR gene is retained in T lymphocyte-derived human iPSCs, which can be further induced to differentiate into functionally active $\mathrm{T}$ cells [54-56]. Functional, tumor antigen-specific $\mathrm{T}$ lymphocytes can be produced in vitro by reprogramming selected T cells into iPSCs which then differentiate back into $\mathrm{T}$ lymphocytes for infusion into patients. However, the safety of $\mathrm{T}$ cell-derived human iPSCs must be further validated.

\section{Targeting CSCs}

CSCs are multipotent, can self-renew, and have high proliferative capacities, contributing to rapid activation of tumor invasion and metastasis. Therefore, targeting CSCs is vital to ensuring high therapeutic efficacies and preventing tumor recurrence [3]. Since CSCs can attract normal stem cells, normal stem cells can be potentially used to target CSCs in cancer therapy. Interactions between normal stem cells and CSCs suppress tumor proliferation, angiogenesis, and metastasis, and reduce inflammation and apoptosis. Bryukhovetskiy, et al. assessed the potential of NSCs and HSCs in anti-glioblastoma therapy [57], and concluded that HSCs may be ideal for developing technologies aimed at controlling glioblastoma CSC activity, as HSCs are less prone to neoplastic transformation in neural tumors than NSCs. Similarly, engineered HSCs may facilitate the generation of cell systems that can trigger targeted CSC apoptosis [58].

\section{Anticancer drug screening}

In addition to treating cancers directly, iPSCs can be used to screen new anticancer drugs. Differentiating patient cancer tissue-derived iPSCs generates cell types that may be more biologically related to human tumors than currently available drug screening methods, such as traditional cancer cell lines, mouse xenograft models, and mouse tumors. Additionally, hepatotoxicity prevents many potential antitumor drugs from being clinically applied, and can be screened for using hepatocytes produced from human iPSCs with various genetic backgrounds [59]. The applications of stem cells in cancer therapy are listed in Table 1.

\section{FACTORS INFLUENCING STEM CELL THERAPIES}

\section{Stem cell type}

While stem cells share similar properties, their therapeutic effects may differ. Ahmed, et al. first compared NSCs with MSCs as carriers for an oncolytic adenovirus in a glioma model. Both stem cell types supported intracellular adenoviral replication, but a log more virus was released from NSCs than from MSCs $(p<0.001)$. 
Additionally, only intracranial administration of virusloaded NSCs prolonged survival in an animal model of orthotopic glioma (median survival for MSCs: 44 days vs. that for NSCs: 68.5 days, $p<0.002$ ) [60]. NSCs exhibited superior therapeutic efficacy in intracranial tumors compared to MSCs, despite comparable migration capacities, suggesting that carrier trafficking efficacy may be closely linked to the level of relatedness between carrier origin cells and malignant cells [60].

In anti-cancer therapy, the choice of stem cell type depends on cell-specific characteristics and therapeutic requirements. To treat hematologic and non-hematologic malignancies, autologous HSC transplantation is frequently used to rescue hematopoiesis after high-dose chemotherapy. Upon congenital and acquired marrow failures, this method is also widely used to continuously meet mature blood cell replenishment requirements [61]. iPSCs are also better than other stem cells for assessing candidate antitumor drug toxicities [62].

\section{Route of transplantation}

The route of stem cell delivery plays a critical role in anti-tumor therapy [60]. An appropriate method must consider target pathology, therapeutic objectives, and patient risk-benefit profile. In murine models of GBM, efficient NSC delivery is achieved via contralateral injection into the tumor site [63]. However, intracranial injections are invasive and not ideal for repeated operations. NSCs delivered intranasally can still efficiently migrate to tumor tissues [64], allowing repeated administration [65]. This approach can also avoid intravascular delivery-related complications, such as pulmonary embolism, obstruction by the blood brain barrier, and infarctions [64].

Compared with cell suspension injections, semisolid substrates may augment transplantation efficiencies by providing mechanical support and relieving metabolic stress. Currently, poor survival of NSC grafts can be tentatively counteracted by transplantation of stem cells utilizing biocompatible devices. Hansen, et al. reported a three-dimensional extracellular matrix-based substrate (3DECM), purified from engineered skin cultures, that could provide an efficient clinical administration route for cell grafts. 3DCEM enabled in vitro expansion of embedded NSCs, retaining their uncommitted differentiation [66].

\section{Cell number and transplantation timing}

Treatment outcomes are affected by transplanted cell numbers and transplantation timing. Transplantation of an insufficient number of HSCs in patients with oncohematological diseases results in inefficient hematopoietic component replacement, and diseases easily relapse [61]. However, a too-large number of transplanted cells may increase the risk of teratoma formation or ectopic engraftment. Thus, the number of cells for effective treatment should be optimized.

Stem cell therapy efficacy depends on administration timing. For example, NSCs should be given before ionizing radiation (XRT) and temozolomide (TMZ). Alex, et al. reported that loaded NSCs given to GBM43 xenografted animals prior to XRT-TMZ treatment increased median survival by 9 days over that of animals receiving a reverse schedule $(p<0.05)$ [35]. Additionally, $33 \%$ of mice receiving loaded NSCs prior to TMZ-XRT lived $\geq 70$ days, compared to only $9 \%$ of mice receiving the reverse regimen. Furthermore, loaded NSC administration before XRT-TMZ treatment promoted mouse brain tumor cell apoptosis.

For oncolytic virotherapy, carrier cells must first accumulate in tumor beds. Then, viral progeny are released to allow targeted delivery of the functioning virus. Thaci, et al. found that maximum viral progeny were released from NSCs seven days after loading in vitro; ideally, carrier cells should reach tumor sites prior to this time [67]. Most NSCs migrated to tumor sites within 24-48 hours after implantation [68]. Thus, oncolytic viruses delivered via NSCs should have replication cycles appropriate for NSC tumor-homing abilities.

\section{CHALLENGES TO STEM CELL THERAPY}

\section{Treatment durability}

Tumors commonly relapse regardless of strong initial therapeutic effects. Like most chemotherapies, stem cell therapy using a single agent generally cannot eliminate tumors. Therefore, an optimum drug combination should be rationally selected [6]. Many combination therapies have been tested to improve treatment durability. For example, IFN- $\beta$ immunotherapy combined with chemotherapy using a prodrug/suicide gene system has shown synergistic therapeutic effects against human colorectal cancer [69]. Irradiating tumor cells can induce production of factors that stimulate MSC invasion through integral basement membranes, increasing the number of MSCs in tumors [70]. Combining stem cell-based oncolytic virotherapy with chemoradiotherapy can minimize residual disease volumes and sensitize glioma cells to CRAd-S-pk7 (OV CRAd-Survivin-pk7) during radiotherapy [35]. Kim, et al. [71] found that TMZ sensitized glioma cells to TRAIL-induced apoptosis by modulating the apoptotic machinery, and enhanced MSC-TRAIL gene therapy antitumor effects. Epidermal growth factor receptor (EGFR), which is mutated and overexpressed in various tumors, is associated with poor prognosis and shortened survival [72]. TRAIL combined with stem cell-delivered immunoconjugates of EGFRspecific nanobodies enhanced treatment outcomes [73]. 


\section{Potential tumorigenesis concerns}

Normal stem cells share some characteristics with CSCs, including self-renewal, differentiation, and epithelial-to-mesenchymal transition capacities. Stem cell therapy may increase cancer risk, as evidence by tumor formation four years after fetal neural stem cell transplantation for ataxia-telangiectasia [74]. Thus, prevention of tumor formation by transplanted stem cells requires additional study [63]. However, whether stem cells promote the growth of certain tumors or form tumors themselves is uncertain. Karnoub, et al. demonstrated that bone-marrow-derived MSCs mixed with otherwise weakly metastatic human breast carcinoma cells increased the cancer cells' metastatic potentials, allowing for tumor formation in subcutaneous xenografts [75]. The breast cancer cells promoted MSC secretion of chemokine CCL5, which acted in a paracrine fashion to increase cancer cell motility, invasion, and metastasis. Increased breast cancer cell metastatic capability was reversible and dependent on CCL5 signaling through the chemokine receptor, CCR5. Therefore, MSCs in the tumor microenvironment facilitated metastasis by reversibly changing cancer cell phenotypes.

Rosland, et al. [76] showed that spontaneous malignant transformation occurred in $45.8 \%(11 / 24)$ of bone marrow-derived MSC long-term (5-106 weeks) cultures, indicating spontaneous malignant transformation. In vitro cell culture conditions may initiate stress-induced genomic instability, promoting the malignant phenotype. Mutation tendency has also been related to oxygen tension [77] and matrix elasticity [78]. Therefore, optimization of in vitro culture conditions is important for MSC expansion for clinical use. However, other groups present contradictory findings regarding MSC transformation tendencies. Bernardo, et al. reported that MSC remain stable and do not transform in long-term cultures [79]. Thus, stem cell fates may be largely dependent on culture environments, and implanted stem cells may contribute to the growth of certain tumors or produce tumors themselves.

Multipotent NSCs, MSCs, and HSCs appear safer for clinical use than ESCs and iPSCs. Most studies focus on pluripotent stem cells that may be highly tumorigenic. There are six strategies to eliminate any possibility of neoplastic transformation [80]. First, undifferentiated pluripotent stem cells, which are potentially tumorigenic, can be excluded from clinical preparations using antibodies that target specific surface-displayed biomarkers. Stem cell differentiation downregulates display of these biomarkers. Monoclonal antibodies may facilitate fluorescence activated cell sorting or magnetic activated cell sorting of undifferentiated, pluripotent stem cells modified with fluorochromes or superparamagnetic chelates, respectively. Second, directed differentiation of iPSCs includes monitoring the expression of differentiation lineage-specific genes. Successfully differentiated cells can be identified and sorted using recombinant reporter proteins. GFP and similar proteins work well as reporters of undifferentiated vs. differentiated cells. Undifferentiated pluripotent stem cells transformed to express GFP emit telltale fluorescence upon illumination with specific wavelengths as long as they remain undifferentiated. This facilitates their sorting out or eradication through laser ablation. Third, undifferentiated cells can be killed using toxic antibodies or antibody-guided toxins. For example, monoclonal antibodies against claudin-6, a biomarker for undifferentiated pluripotent ESCs and iPSCs, can guide toxins to these stem cells for selective, targeted killing [81]. Fourth, undifferentiated stem cells can be eradicated using cytotoxic agents, which can be applied to selectively kill pluripotent stem cells that could develop into tumors. PluriSIn\#1 inhibits stearoyl-CoA desaturase-1, an enzyme involved in monounsaturated fatty acid metabolism, and induces apoptosis in treated cells [82]. PluriSIn\#1 treatment selectively eliminates undifferentiated iPSCs and ESCs [83]. Fifth, potentially tumorigenic stem cells can be sensitized to prodrugs through transformation using suicide genes. The enzyme/prodrug cancer therapy strategy can also be adapted to kill undifferentiated stem cells. For example, hESCs engineered to express the HSV-TK gene were killed following GCV treatment, whereas non-transfected hESCs were unaffected [84]. Finally, differentiated refractive stem cells can be eliminated through self-induced transgenic expression of recombinant human DNases. To this end, and to improve treatment safeties and efficacies, a toxic reagentindependent feedback loop was developed to select for differentiated stem cells [85]. iPSCs were directed to differentiate into endothelial or myocardial lineages, and were then transfected with human recombinant DNASE1, DNASE1L3, DNASE2, and DFFB, guided by antiSSEA-4 and anti-TRA-1-60 synthetic antibodies. Transgenes were delivered only to pluripotent, differentiation-refractive stem cells. Thus, iPSCs that maintained their pluripotency and specific cell surface display profiles, and continued proliferating instead of differentiating, expressed the human recombinant DNases. Genomic DNA was degraded in these potentially tumorigenic stem cells, ultimately killing the cells. These six strategies could safeguard against tumor transformation in stem cell population.

\section{CONCLUSIONS}

Stem cell technologies may open new doors for cancer therapy. Stem cells migrate to solid tumors and micrometastatic lesions, facilitating site-specific anti-tumor agent delivery. Stem cells can be engineered to stably express a variety of antitumor agents, overcoming the short half-lives of conventional chemotherapeutic agents. However, conquering stem cell therapy limitations will require additional research to better illuminate relationships 
between normal and cancer stem cells. A better understanding of fundamental stem cell mechanisms will improve stem cell-based regenerative medicine and anticancer strategies, and is imperative for more widespread clinical utilization of stem cell-based therapies.

\section{Abbreviations}

ESCs, embryonic stem cells; SSCs, somatic stem cells; HSCs, hematopoietic stem cells; NSCs, neural stem cells; MSCs, mesenchymal stem cells; iPSCs, induced pluripotent stem cells; EPCs, embyronic progenitor and stem cells; CSCs, cancer stem cells; SDF1, stromal cell-derived factor 1; CXCR4, CXCchemokine receptor 4; CXCL, CXC-chemokine ligand; 5-FC, 5-fluorocytosine; GBMs, glioblastomas; CD, deaminase; $\mathrm{CE}$, carboxylesterase; anti-HER2Ab, anti epidermal growth factor receptor 2 antibody; HSV-TK. herpes simplex virus-thymidine kinase; GCV, ganciclovir ; GCV-TP, triphosphate ganciclovir; TRAIL, TNF $\alpha$-related apoptosis-inducing ligand; S-TRAIL, secretable TNF $\alpha$-related apoptosis-inducing ligand; sECM, synthetic extracellular matrix sECM; OV, oncolytic viral; NP, Nanoparticle; IFN- $\beta$, interferon- $\beta$; Stat 3 , signal transducer activator transcription factor 3 ; oHSV, oncolytic herpes simplex virus; CARs, chimeric antigen receptors; TCR, T-cell receptors; 3DECM, 3-dimensional extracellular matrix-based substrate; XRT, ionizing radiation; TMZ, temozolomide; CRAd-S-pk7, OV CRAd-Survivin-pk7; EGFR, Epidermal growth factor receptor EGFR.

\section{Author contributions}

Chengliang Zhang and Ting Huang conceived of and contributed equally to the manuscript.

\section{ACKNOWLEDGMENTS}

The study was partially supported by the National Natural Science Foundation of China (grant number 81301953).

\section{CONFLICTS OF INTEREST}

The authors declare no conflicts of interest.

\section{REFERENCES}

1. Tran C, Damaser MS. Stem cells as drug delivery methods: application of stem cell secretome for regeneration. Adv Drug Deliv Rev. 2015; 82-83:1-11.

2. Seita J, Rossi DJ, Weissman IL. Differential DNA damage response in stem and progenitor cells. Cell Stem Cell. 2010; $7: 145-147$.
3. Xiao J, Mu J, Liu T, Xu H. Dig the root of cancer: targeting cancer stem cells therapy. Journal of Medical Discovery. 2017:D17003.

4. Lin HT, Otsu M, Nakauchi H. Stem cell therapy: an exercise in patience and prudence. Philos Trans R Soc Lond B Biol Sci. 2013; 368:20110334.

5. Takahashi K, Yamanaka S. Induction of pluripotent stem cells from mouse embryonic and adult fibroblast cultures by defined factors. Cell. 2006; 126:663-676.

6. Bago JR, Sheets KT, Hingtgen SD. Neural stem cell therapy for cancer. Methods. 2016; 99:37-43.

7. Kanojia D, Balyasnikova IV, Morshed RA, Frank RT, Yu D, Zhang L, Spencer DA, Kim JW, Han Y, Yu D, Ahmed AU, Aboody KS, Lesniak MS. Neural stem cells secreting anti-her2 antibody improve survival in a preclinical model of her 2 overexpressing breast cancer brain metastases. Stem Cells. 2015; 33:2985-2994.

8. Lee HJ, Doo SW, Kim DH, Cha YJ, Kim JH, Song YS, Kim SU. Cytosine deaminase-expressing human neural stem cells inhibit tumor growth in prostate cancer-bearing mice. Cancer Lett. 2013; 335:58-65.

9. Yi BR, Kim SU, Choi KC. Co-treatment with therapeutic neural stem cells expressing carboxyl esterase and CPT11 inhibit growth of primary and metastatic lung cancers in mice. Oncotarget. 2014; 5:12835-12848. https://doi. org/10.18632/oncotarget.2547.

10. Goligorsky MS, Salven P. Concise review: endothelial stem and progenitor cells and their habitats. Stem Cells Transl Med. 2013; 2:499-504.

11. Asahara T, Murohara T, Sullivan A, Silver M, van der Zee R, Li T, Witzenbichler B, Schatteman G, Isner JM. Isolation of putative progenitor endothelial cells for angiogenesis. Science. 1997; 275:964-967.

12. Dawood S, Austin L, Cristofanilli M. Cancer stem cells: implications for cancer therapy. Oncology (Williston Park). 2014; 28:1101-1107, 1110.

13. Bernardo ME, Fibbe WE. Mesenchymal stromal cells: sensors and switchers of inflammation. Cell Stem Cell. $2013 ; 13: 392-402$.

14. Milwid JM, Elman JS, Li M, Shen K, Manrai A, Gabow A, Yarmush J, Jiao Y, Fletcher A, Lee J, Cima MJ, Yarmush ML, Parekkadan B. Enriched protein screening of human bone marrow mesenchymal stromal cell secretions reveals MFAP5 and PENK as novel IL-10 modulators. Mol Ther. 2014; 22:999-1007.

15. Motaln H, Gruden K, Hren M, Schichor C, Primon M, Rotter A, Lah TT. Human mesenchymal stem cells exploit the immune response mediating chemokines to impact the phenotype of glioblastoma. Cell Transplant. 2012; 21:1529-1545.

16. Aboody KS, Brown A, Rainov NG, Bower KA, Liu S, Yang W, Small JE, Herrlinger U, Ourednik V, Black PM, Breakefield XO, Snyder EY. Neural stem cells display extensive tropism for pathology in adult brain: evidence from intracranial gliomas. Proc Natl Acad Sci USA. 2000; 97:12846-12851. 
17. Khurana S, Margamuljana L, Joseph C, Schouteden S, Buckley SM, Verfaillie CM. Glypican-3-mediated inhibition of CD26 by TFPI: a novel mechanism in hematopoietic stem cell homing and maintenance. Blood. 2013; 121:2587-2595.

18. Eseonu OI, De Bari C. Homing of mesenchymal stem cells: mechanistic or stochastic? Implications for targeted delivery in arthritis. Rheumatology (Oxford). 2015; 54:210-218.

19. Suarez-Alvarez B, Lopez-Vazquez A, Lopez-Larrea C. Mobilization and homing of hematopoietic stem cells. Adv Exp Med Biol. 2012; 741:152-170.

20. Park SA, Ryu CH, Kim SM, Lim JY, Park SI, Jeong CH, Jun JA, Oh JH, Park SH, Oh W, Jeun SS. CXCR4-transfected human umbilical cord blood-derived mesenchymal stem cells exhibit enhanced migratory capacity toward gliomas. Int J Oncol. 2011; 38:97-103.

21. Koizumi S, Gu C, Amano S, Yamamoto S, Ihara H, Tokuyama T, Namba H. Migration of mouse-induced pluripotent stem cells to glioma-conditioned medium is mediated by tumor-associated specific growth factors. Oncol Lett. 2011; 2:283-288.

22. Naderi-Meshkin H, Bahrami AR, Bidkhori HR, Mirahmadi M, Ahmadiankia N. Strategies to improve homing of mesenchymal stem cells for greater efficacy in stem cell therapy. Cell Biol Int. 2015; 39:23-34.

23. Schantz JT, Chim H, Whiteman M. Cell guidance in tissue engineering: SDF-1 mediates site-directed homing of mesenchymal stem cells within three-dimensional polycaprolactone scaffolds. Tissue Eng. 2007; 13:2615-2624.

24. Aboody KS, Najbauer J, Metz MZ, D’Apuzzo M, Gutova M, Annala AJ, Synold TW, Couture LA, Blanchard S, Moats RA, Garcia E, Aramburo S, Valenzuela VV, Frank RT, Barish ME, Brown CE, et al. Neural stem cell-mediated enzyme/prodrug therapy for glioma: preclinical studies. Sci Transl Med. 2013; 5:159r-184r.

25. Altaner C, Altanerova V, Cihova M, Ondicova K, Rychly B, Baciak L, Mravec B. Complete regression of glioblastoma by mesenchymal stem cells mediated prodrug gene therapy simulating clinical therapeutic scenario. Int J Cancer. 2014; 134:1458-1465.

26. Aboody KS, Najbauer J, Danks MK. Stem and progenitor cell-mediated tumor selective gene therapy. Gene Ther. 2008; 15:739-752.

27. Martinez-Quintanilla $J$, Bhere $\mathrm{D}$, Heidari $\mathrm{P}$, He D, Mahmood U, Shah K. Therapeutic efficacy and fate of bimodal engineered stem cells in malignant brain tumors. Stem Cells. 2013; 31:1706-1714.

28. Li S, Tokuyama T, Yamamoto J, Koide M, Yokota N, Namba H. Bystander effect-mediated gene therapy of gliomas using genetically engineered neural stem cells. Cancer Gene Ther. 2005; 12:600-607.

29. Zhao Y, Lam DH, Yang J, Lin J, Tham CK, Ng WH, Wang S. Targeted suicide gene therapy for glioma using human embryonic stem cell-derived neural stem cells genetically modified by baculoviral vectors. Gene Ther. 2012; 19:189-200.
30. Stuckey DW, Shah K. TRAIL on trial: preclinical advances in cancer therapy. Trends Mol Med. 2013; 19:685-694.

31. Duiker EW, Dijkers EC, Lambers HH, de Jong S, van der Zee AG, Jager PL, Kosterink JG, de Vries EG, Lub-de HM. Development of a radioiodinated apoptosis-inducing ligand, rhTRAIL, and a radiolabelled agonist TRAIL receptor antibody for clinical imaging studies. Br J Pharmacol. 2012; 165:2203-2212.

32. Kauer TM, Figueiredo JL, Hingtgen S, Shah K. Encapsulated therapeutic stem cells implanted in the tumor resection cavity induce cell death in gliomas. Nat Neurosci. 2011; 15:197-204.

33. Ling X, Marini F, Konopleva M, Schober W, Shi Y, Burks J, Clise-Dwyer K, Wang RY, Zhang W, Yuan X, Lu H, Caldwell L, Andreeff M. Mesenchymal Stem Cells Overexpressing IFN-beta Inhibit Breast Cancer Growth and Metastases through Stat3 Signaling in a Syngeneic Tumor Model. Cancer Microenviron. 2010; 3:83-95.

34. Wollmann G, Ozduman K, van den Pol AN. Oncolytic virus therapy for glioblastoma multiforme: concepts and candidates. Cancer J. 2012; 18:69-81.

35. Tobias AL, Thaci B, Auffinger B, Rincon E, Balyasnikova IV, Kim CK, Han Y, Zhang L, Aboody KS, Ahmed AU, Lesniak MS. The timing of neural stem cell-based virotherapy is critical for optimal therapeutic efficacy when applied with radiation and chemotherapy for the treatment of glioblastoma. Stem Cells Transl Med. 2013; 2:655-666.

36. Pulkkanen KJ, Yla-Herttuala S. Gene therapy for malignant glioma: current clinical status. Mol Ther. 2005; 12:585-598.

37. Ong HT, Federspiel MJ, Guo CM, Ooi LL, Russell SJ, Peng KW, Hui KM. Systemically delivered measles virusinfected mesenchymal stem cells can evade host immunity to inhibit liver cancer growth. J Hepatol. 2013; 59:999-1006.

38. Duebgen M, Martinez-Quintanilla J, Tamura K, Hingtgen S, Redjal N, Wakimoto H, Shah K. Stem cells loaded with multimechanistic oncolytic herpes simplex virus variants for brain tumor therapy. J Natl Cancer Inst. 2014; 106:u90.

39. Auffinger B, Morshed R, Tobias A, Cheng Y, Ahmed AU, Lesniak MS. Drug-loaded nanoparticle systems and adult stem cells: a potential marriage for the treatment of malignant glioma? Oncotarget. 2013; 4:378-396. https:// doi.org/10.18632/oncotarget.937.

40. Mooney R, Roma L, Zhao D, Van Haute D, Garcia E, Kim SU, Annala AJ, Aboody KS, Berlin JM. Neural stem cellmediated intratumoral delivery of gold nanorods improves photothermal therapy. Acs Nano. 2014; 8:12450-12460.

41. Roger M, Clavreul A, Venier-Julienne MC, Passirani C, Sindji L, Schiller P, Montero-Menei C, Menei P. Mesenchymal stem cells as cellular vehicles for delivery of nanoparticles to brain tumors. Biomaterials. 2010; 31:8393-8401.

42. Li L, Guan Y, Liu H, Hao N, Liu T, Meng X, Fu C, Li Y, Qu Q, Zhang Y, Ji S, Chen L, Chen D, Tang F. Silica nanorattledoxorubicin-anchored mesenchymal stem cells for tumortropic therapy. Acs Nano. 2011; 5:7462-7470. 
43. Okabe M, Otsu M, Ahn DH, Kobayashi T, Morita Y, Wakiyama Y, Onodera M, Eto K, Ema H, Nakauchi H. Definitive proof for direct reprogramming of hematopoietic cells to pluripotency. Blood. 2009; 114:1764-1767.

44. Francisco Barriga NR, Wietstruck A. Alternative Donor Sources for Hematopoietic Stem Cell Transplantation. Intech. 2013.

45. Liu H, Kim Y, Sharkis S, Marchionni L, Jang YY. In vivo liver regeneration potential of human induced pluripotent stem cells from diverse origins. Sci Transl Med. 2011; 3:39r-82r.

46. Choi SM, Kim Y, Liu H, Chaudhari P, Ye Z, Jang YY. Liver engraftment potential of hepatic cells derived from patientspecific induced pluripotent stem cells. Cell Cycle. 2011; 10:2423-2427.

47. Renga M, Pedrazzoli P, Siena S. Present results and perspectives of allogeneic non-myeloablative hematopoietic stem cell transplantation for treatment of human solid tumors. Ann Oncol. 2003; 14:1177-1184.

48. Morecki S, Moshel Y, Gelfend Y, Pugatsch T, Slavin S. Induction of graft vs. tumor effect in a murine model of mammary adenocarcinoma. International Journal of Cancer Journal International Du Cancer. 1997; 71:59-63.

49. Bertz H, Illerhaus G, Veelken H, Finke J. Allogeneic hematopoetic stem-cell transplantation for patients with relapsed or refractory lymphomas: comparison of highdose conventional conditioning versus fludarabine-based reduced-intensity regimens. Ann Oncol. 2002; 13:135-139.

50. Gschweng E, De Oliveira S, Kohn DB. Hematopoietic stem cells for cancer immunotherapy. Immunol Rev. 2014; 257:237-249.

51. Vatakis DN, Koya RC, Nixon CC, Wei L, Kim SG, Avancena P, Bristol G, Baltimore D, Kohn DB, Ribas A, Radu CG, Galic Z, Zack JA. Antitumor activity from antigen-specific CD8 $\mathrm{T}$ cells generated in vivo from genetically engineered human hematopoietic stem cells. Proc Natl Acad Sci USA. 2011; 108:E1408-E1416.

52. Karan D, Dubey S, Van Veldhuizen P, Holzbeierlein JM, Tawfik O, Thrasher JB. Dual antigen target-based immunotherapy for prostate cancer eliminates the growth of established tumors in mice. Immunotherapy-UK. 2011; 3:735-746.

53. Serwold T, Hochedlinger K, Swindle J, Hedgpeth J, Jaenisch R, Weissman IL. T-cell receptor-driven lymphomagenesis in mice derived from a reprogrammed $\mathrm{T}$ cell. Proc Natl Acad Sci USA. 2010; 107:18939-18943.

54. Brown ME, Rondon E, Rajesh D, Mack A, Lewis R, Feng X, Zitur LJ, Learish RD, Nuwaysir EF. Derivation of induced pluripotent stem cells from human peripheral blood $\mathrm{T}$ lymphocytes. PLoS One. 2010; 5:e11373.

55. Loh YH, Hartung O, Li H, Guo C, Sahalie JM, Manos PD, Urbach A, Heffner GC, Grskovic M, Vigneault F, Lensch MW, Park IH, Agarwal S, et al. Reprogramming of T cells from human peripheral blood. Cell Stem Cell. 2010; 7:15-19.
56. Seki T, Yuasa S, Oda M, Egashira T, Yae K, Kusumoto D, Nakata H, Tohyama S, Hashimoto H, Kodaira M, Okada Y, Seimiya H, Fusaki N, et al. Generation of induced pluripotent stem cells from human terminally differentiated circulating $\mathrm{T}$ cells. Cell Stem Cell. 2010; 7:11-14.

57. Bryukhovetskiy IS, Dyuizen IV, Shevchenko VE, Bryukhovetskiy AS, Mischenko PV, Milkina EV, Khotimchenko YS. Hematopoietic stem cells as a tool for the treatment of glioblastoma multiforme. Mol Med Rep. 2016; 14:4511-4520.

58. Bryukhovetskiy IS, Mischenko PV, Tolok EV, Khotimchenko YS, Zaitsev SV, Bryukhovetskiy AS. Hematopoietic stem cells with induced apoptosis effectively inhibit glioma cell growth in vitro, but started new mechanism of tumor stem cells. Genes and Cells. 2014; 9:70-75.

59. Wilke RA, Lin DW, Roden DM, Watkins PB, Flockhart D, Zineh I, Giacomini KM, Krauss RM. Identifying genetic risk factors for serious adverse drug reactions: current progress and challenges. Nat Rev Drug Discov. 2007; 6:904-916.

60. Miska J, Lesniak MS. Neural Stem Cell Carriers for the Treatment of Glioblastoma Multiforme. EBioMedicine. 2015; 2:774-775.

61. Golubeva V, Mikhalevich J, Novikova J, Tupizina O, Trofimova S, Zueva Y. Novel cell population data from a haematology analyzer can predict timing and efficiency of stem cell transplantation. Transfus Apher Sci. 2014; 50:39-45.

62. Sharkis SJ, Jones RJ, Civin C, Jang YY. Pluripotent stem cell-based cancer therapy: promise and challenges. Sci Transl Med. 2012; 4:127p-129p.

63. Ahmed AU, Thaci B, Tobias AL, Auffinger B, Zhang L, Cheng Y, Kim CK, Yunis C, Han Y, Alexiades NG, Fan X, Aboody KS, Lesniak MS. A preclinical evaluation of neural stem cell-based cell carrier for targeted antiglioma oncolytic virotherapy. J Natl Cancer Inst. 2013; 105:968-977.

64. Balyasnikova IV, Prasol MS, Ferguson SD, Han Y, Ahmed AU, Gutova M, Tobias AL, Mustafi D, Rincon E, Zhang L, Aboody KS, Lesniak MS. Intranasal delivery of mesenchymal stem cells significantly extends survival of irradiated mice with experimental brain tumors. Mol Ther. $2014 ; 22: 140-148$.

65. Schmidt NO, Dührsen L, Reitz M, Henze M, Sedlacik J, Riecken K, Fehse B, Westphal M. Repeated intranasal application of neural stem cell-mediated enzym/prodrug therapy using a novel Hsv-thymidine kinase variant improves therapeutic efficiency in an intracranial glioblastoma model. Neuro-Oncology. 2014; 16:i50.

66. Hansen K, Muller FJ, Messing M, Zeigler F, Loring JF, Lamszus K, Westphal M, Schmidt NO. A 3-dimensional extracellular matrix as a delivery system for the transplantation of glioma-targeting neural stem/progenitor cells. Neuro Oncol. 2010; 12:645-654.

67. Thaci B, Ahmed AU, Ulasov IV, Tobias AL, Han Y, Aboody KS, Lesniak MS. Pharmacokinetic study of neural stem 
cell-based cell carrier for oncolytic virotherapy: targeted delivery of the therapeutic payload in an orthotopic brain tumor model. Cancer Gene Ther. 2012; 19:431-442.

68. Ahmed AU, Thaci B, Alexiades NG, Han Y, Qian S, Liu F, Balyasnikova IV, Ulasov IY, Aboody KS, Lesniak MS. Neural stem cell-based cell carriers enhance therapeutic efficacy of an oncolytic adenovirus in an orthotopic mouse model of human glioblastoma. Mol Ther. 2011; 19:1714-1726.

69. Yi BR, Park MA, Lee HR, Kang NH, Choi KJ, Kim SU, Choi KC. Suppression of the growth of human colorectal cancer cells by therapeutic stem cells expressing cytosine deaminase and interferon-beta via their tumor-tropic effect in cellular and xenograft mouse models. Mol Oncol. 2013; 7:543-554.

70. Zielske SP, Livant DL, Lawrence TS. Radiation increases invasion of gene-modified mesenchymal stem cells into tumors. Int J Radiat Oncol Biol Phys. 2009; 75:843-853.

71. Kim SM, Woo JS, Jeong CH, Ryu CH, Jang JD, Jeun SS. Potential application of temozolomide in mesenchymal stem cell-based TRAIL gene therapy against malignant glioma. Stem Cells Transl Med. 2014; 3:172-182.

72. Huang PH, Xu AM, White FM. Oncogenic EGFR signaling networks in glioma. Sci Signal. 2009; 2:e6.

73. van de Water JA, Bagci-Onder T, Agarwal AS, Wakimoto H, Roovers RC, Zhu Y, Kasmieh R, Bhere D, Van Bergen EHP, Shah K. Therapeutic stem cells expressing variants of EGFR-specific nanobodies have antitumor effects. Proc Natl Acad Sci USA. 2012; 109:16642-16647.

74. Amariglio N, Hirshberg A, Scheithauer BW, Cohen Y, Loewenthal R, Trakhtenbrot L, Paz N, Koren-Michowitz M, Waldman D, Leider-Trejo L, Toren A, Constantini S, Rechavi G. Donor-derived brain tumor following neural stem cell transplantation in an ataxia telangiectasia patient. Plos Med. 2009; 6:e1000029.

75. Karnoub AE, Dash AB, Vo AP, Sullivan A, Brooks MW, Bell GW, Richardson AL, Polyak K, Tubo R, Weinberg RA. Mesenchymal stem cells within tumour stroma promote breast cancer metastasis. Nature. 2007; 449:557-563.

76. Rosland GV, Svendsen A, Torsvik A, Sobala E, McCormack E, Immervoll H, Mysliwietz J, Tonn JC, Goldbrunner R, Lonning PE, Bjerkvig R, Schichor C. Long-term cultures of bone marrow-derived human mesenchymal stem cells frequently undergo spontaneous malignant transformation. Cancer Res. 2009; 69:5331-5339.
77. Busuttil RA, Rubio M, Dolle ME, Campisi J, Vijg J. Oxygen accelerates the accumulation of mutations during the senescence and immortalization of murine cells in culture. Aging Cell. 2003; 2:287-294.

78. Engler AJ, Sen S, Sweeney HL, Discher DE. Matrix elasticity directs stem cell lineage specification. Cell. 2006; 126:677-689.

79. Bernardo ME, Zaffaroni N, Novara F, Cometa AM, Avanzini MA, Moretta A, Montagna D, Maccario R, Villa R, Daidone MG. Human bone marrow derived mesenchymal stem cells do not undergo transformation after long-term in vitro culture and do not exhibit telomere maintenance mechanisms. Cancer Res. 2007; 67:9142.

80. Malecki M. 'Above all, do no harm': safeguarding pluripotent stem cell therapy against iatrogenic tumorigenesis. Stem Cell Res Ther. 2014; 5:73.

81. Ben-David U, Nudel N, Benvenisty N. Immunologic and chemical targeting of the tight-junction protein Claudin- 6 eliminates tumorigenic human pluripotent stem cells. Nat Commun. 2013; 4:1992.

82. Lim DY, Ng YH, Lee J, Mueller M, Choo AB, Wong VV. Cytotoxic antibody fragments for eliminating undifferentiated human embryonic stem cells. J Biotechnol. 2011; 153:77-85.

83. Ben-David U, Gan QF, Golan-Lev T, Arora P, Yanuka O, Oren YS, Leikin-Frenkel A, Graf M, Garippa R, Boehringer M. Selective elimination of human pluripotent stem cells by an oleate synthesis inhibitor discovered in a highthroughput screen. Cell Stem Cell. 2013; 12:167.

84. Schuldiner M, Itskovitz-Eldor J, Benvenisty N. Selective ablation of human embryonic stem cells expressing a "suicide" gene. Stem Cells. 2003; 21:257-265.

85. Malecki M, LaVanne C, Alhambra D, Dodivenaka C, Nagel S, Malecki R. Safeguarding Stem Cell-Based Regenerative Therapy against Iatrogenic Cancerogenesis: Transgenic Expression of DNASE1, DNASE1L3, DNASE2, DFFB Controlled By POLA1 Promoter in Proliferating and Directed Differentiation Resisting Human Autologous Pluripotent Induced Stem Cells Leads to their Death. J Stem Cell Res Ther. 2013; Suppl 9:201559. 